\title{
Testicular Translocator Protein Expression is Differentially Altered by Synthetic Cannabinoid HU210 in Adult and Adolescent Rats
}

\author{
Ronald Ho Yeung Chan ${ }^{1,2^{\star}}$, Winnie Wai-Ying Kam ${ }^{1-3}$, Guo Jun Liu ${ }^{1,2}$, Katerina Zavitsanou ${ }^{4-6}$ and Richard B Banati ${ }^{1,2,7}$ \\ ${ }^{1}$ ANSTO Life Sciences, Australian Nuclear Science and Technology Organization, Sydney, New South Wales, Australia \\ ${ }^{2}$ Discipline of Medical Radiation Sciences, Faculty of Health Sciences, University of Sydney, New South Wales, Australia \\ ${ }^{3}$ Department of Health Technology and Informatics, Hong Kong Polytechnic University, Hong Kong, China \\ ${ }^{4}$ Schizophrenia Research Institute, Sydney, New South Wales, Australia \\ ${ }^{5}$ School of Psychiatry, University of New South Wales, Sydney, NSW, Australia \\ ${ }^{6}$ Schizophrenia Research Laboratory, Neuroscience Research Australia, Sydney, NSW, Australia
}

7National Imaging Facility (Ramaciotti Imaging Center), Brain and Mind Research Institute, University of Sydney, New South Wales, Australia

"Corresponding author: Ronald Ho Yeung Chan, ANSTO Life Sciences, Australian Nuclear Science and Technology Organization, Sydney, New South Wales, Australia, Tel: + 6129717 3111; E-mail: Ronald.Chan@usyd.edu.au

Received date: September 14, 2014, Accepted date: October 20, 2014, Publication date: October 23, 2014

Copyright:@ 2014 Chan RHY, et al. This is an open-access article distributed under the terms of the Creative Commons Attribution License, which permits unrestricted use, distribution, and reproduction in any medium, provided the original author and source are credited.

\section{Abstract}

Objective: The translocator protein (TSPO) has been implicated in numerous functions including steroid production and regulation of stress and anxiety. Cannabinoids have been shown to reduce plasma testosterone levels and alter anxiety levels. The aim of the present study was to determine whether the synthetic cannabinoid HU210 is able to regulate TSPO expression in several peripheral organs.

Methods: HU210 $(100 \mu \mathrm{g} / \mathrm{kg})$ was administered intraperitoneally to both adult and adolescent male ratsfor 14 days. TSPO receptor expression in several organs, including the liver, spleen, kidneys and testes, was quantified by membrane receptor binding using the selective radiolig and, PK11195. In cases where receptor binding data indicated significant cannabinoid-induced differences, further RT-qPCR was carried out to determine the transcriptional regulation of the TSPO gene. Additionally, film-autography was used to identify potential changes in the spatial distribution of the TSPO tissue binding sites.

Results: Results indicate that HU210 induces significant reductions in testicular TSPO expression in adult but not adolescent rats. No changes were found in other organs examined. These results are consistent with the previously observed effects of cannabinoids on testosterone production and a presumed role for TSPO in steroidogenesis.

Conclusions: Overall, these results suggest that cannabinoids may alter testosterone production by altering the expression of testicular TSPO and that the alteration of TSPO occurs in an age-dependent manner.

Keywords: Adolescent rats; Adult; Cannabinoid; Protein expression

\section{Introduction}

TSPO, previously known as the peripheral benzodiazepine receptor, is a membrane bound protein found mainly on the outer mitochondrial membrane [1]. Found in nearly all tissues, TSPO is highly expressed in steroidogenic tissues such as the adrenals glands and gonads [2]. A myriad of functions have been prescribed to TSPO including cholesterol transport [3,4], steroidogenesis [4,5], stress regulation [6], heme transport $[7,8]$, cell proliferation $[9,10]$, apoptosis $[11,12]$ and immunomodulation $[13,14]$. The protein sequence of TSPO contains a cholesterol binding motif known as the CRAC domain [15]. As such, best characterised function of TSPO is its ability to associate with cholesterol [16] and assist in its transport across the outer mitochondrial membrane, allowing the initiation of steroidogenesis in the mitochondrial matrix $[17,18]$. Further, it has been proposed that the transport of cholesterol across the mitochondrial membranes is the rate-limiting step of steroidogenesis [19]. As TSPO is important to the production of steroids, it has been suggested to play a role in stress and anxiety regulation through the regulation of neurosteroids [20-22]. Neurosteroids such as allopregnanolone and dehydroepiandrosterone have been shown to modulate GABAA receptors and thus affect stress and anxiety responses [23-26]. The connection between TSPO and stress has also been demonstrated in human and animal studies which have found a reversible down regulation of TSPO expression in the blood and peripheral organs in response to chronic stress or anxiety [6].

In males, the production of testosterone occurs primarily in the testicular tissues. Both acute and chronic cannabinoid administration have been shown to reduce testosterone production [27]. This effect appears to be dose dependent [28] and has been well established in both human and animal studies [29,30]. Cannabinoid administration leads to dose-dependent reductions in gonadotropin-stimulated testosterone production [28] but does not interfere with the binding of gonadotropins to their receptors. This suggests that cannabinoids may exert one of its effects locally by regulating steroidogenic pathways. The precise mechanisms by which cannabinoids affect testosterone production are unclear but may involve the inhibition of cholesterol 
esterase and ATPase dependent calcium transport [31,32]. More recent studies involving CB1 knockout mice reveal that cannabinoids are able to act on CB1 receptors on Leydig cells to reduce testosterone production [33].

In addition to its ability to reduce testosterone production, cannabinoids are also well known for their ability to induce euphoria, relaxation and provide a psychological high [34]. Cannabinoid administration has been observed to produce bidirectional effects on stress and anxiety responses. Typically, lower doses have anxiolytic effects and higher doses have anxiogenic effects [35]. Further, differential responses in the adverse properties of cannabinoids have been reported between adult and adolescent animals [36-38] suggesting that adolescent animals experience greater residual impairments and deficits. Similarly, differential responses to cannabinoids between adult and adolescent animals have been found in various neurotransmitter systems, including GABAergic, serotonergic, dopaminergic and cannabinoid receptor systems [39-42].

Given the role of TSPO in steroidogenesis, and stress and anxiety regulation, we examined the effect of a high-dose chronic administration of HU210, a non-specific cannabinoid receptor agonist, on TSPO expression. This effect was examined in both adult and adolescent rats in testicular tissues as well as other peripheral organs.

\section{Methods}

\section{Ethics statement}

All procedures involving animals were approved by the Animal Care and Ethics Committee at the Australian Nuclear Science Technology Organization.

\section{Materials}

HU210 was purchased from Sapphire Biosciences (Waterloo, NSW, Australia). ${ }^{3} \mathrm{H}-\mathrm{PK} 11195$ was purchased from Perkin Elmer (Waltham, MA, USA). TRIzol and RNA reverse transcription related reagents were purchased from Invitrogen (Mulgrave, NSW, Australia). PCR reagents were purchased from BioRad (Gladesville, NSW, Australia). All other reagents unless specified were purchased from SigmaAldrich (Castle Hill, NSW, Australia). Bicinchoninic acid protein assay kit was purchased from Thermo Fisher Scientific (Scoresby, VIC, Australia).

\section{HU210 injection and tissue collection}

Animals were housed in standard laboratory conditions, with food and water supplied freely. Conditions were maintained at $22 \pm 2^{\circ} \mathrm{C}, 60$ $\pm 10 \%$ humidity and a $12 / 12$ light/dark cycle with lights on at 9 a.m and off at 9 p.m. Animals were acclimatised for 1 week before HU210 or vehicle administration, during this time animals were also handled daily to reduce the stress associated with intraperitoneal injections.

HU210 dose and treatment regime were adapted from Verdurand et al. [41]. Briefly, twenty-four male Wistar rats, 12 adults and 12 adolescents, were used in this study. For each age group, animals were randomly assigned into 2 groups: HU210 or vehicle treatment. All animals were weighed daily prior to injection to ensure accurate dosage. HU210 was dissolved in DMSO and tween and suspended in saline in à 1:1:98 part solution. HU210 at $100 \mu \mathrm{g} / \mathrm{kg}$, or vehicle was injected at approximately 10:30 a.m. daily for 14 consecutive days.
Animals were restrained by hand and injected in the lower intraperitoneal area into the intraperitoneal cavity. Adult and adolescent animals were first injected on postnatal day (PND) 78 and 35 respectively and upon completion of HU210 or vehicle administration were aged PND 91 and 48 respectively. Twenty-four hours after the last injection, animals were euthanized by $\mathrm{CO} 2$ overdose and decapitated. Organs were swiftly collected, snap frozen in liquid nitrogen and stored at $-80^{\circ} \mathrm{C}$ until required.

\section{Radioligand membrane binding}

Organs were homogenised in approximately $50 \mathrm{~mL}$ of ice-cold TRIS buffer ( $\mathrm{pH} 7.4)$ and collected by centrifugation at $48000 \mathrm{~g}$. This procedure was then immediately repeated. Following the second centrifugation, samples were resuspended in approximately 50 volumes of ice-cold TRIS buffer and stored at $-80^{\circ} \mathrm{C}$ until required. Protein concentration was measured using a bicinchoninic acid protein assay kit following the manufacturer's instructions.

Total binding was determined by 10 different concentrations of ${ }^{3} \mathrm{H}$ PK11195 ranging from $1.26 \mathrm{nM}$ to $40 \mathrm{nM}$. Non-specific binding was determined by the addition of $5 \mu \mathrm{M}$ PK11195 to replicate tubes containing the 6 lowest concentrations of ${ }^{3} \mathrm{H}-\mathrm{PK} 11195$. Each tube contained $60 \mu \mathrm{g}$ of protein sample and the final reaction mixture was $400 \mu \mathrm{L}$. Each concentration of radioligand in both total and nonspecific binding was performed in triplicates. ${ }^{3} \mathrm{H}-\mathrm{PK} 11195$ bound protein samples were incubated on ice for 90 minutes before harvesting by rapid filtration through glass fibre Whatman GF/C filters presoaked in $0.5 \%$ polyethyleneimine solution. Filters were collected, placed in liquid scintillation cocktail and counted after standing for at least 12 hours at room temperature. Non-specific binding at the 4 highest concentrations was estimated by fitting a linear equation to the experimentally obtained values for non-specific binding. Bmax and $\mathrm{Kd}$ values were fitted by non-linear regression using GraphPad Prism version 5.04 for Windows (Graph Pad Software, San Diego, CA, USA).

\section{RNA isolation and RT-Qpcr}

Total RNA from testicular samples was isolated using TRIzol reagent following manufacturer's instructions. RNA concentration was determined using the Nanodrop 2000c spectrophotometer (Thermo Fisher Scientific, Scoresby, VIC, Australia) and purity was assessed by both $260 / 280$ and $260 / 230 \mathrm{~nm}$ ratios. RNA quality was examined by $28 \mathrm{~S} / 18 \mathrm{~S}$ ratios following electrophoresis on $1 \%$ agarose gel. Firststrand cDNA was synthesized by reverse transcription of $5 \mu \mathrm{g}$ of RNA using SuperScript III First-Strand Synthesis SuperMix following manufacturer's instructions. Following cDNA synthesis, samples were diluted equally with DEPC treated water and stored at $-20^{\circ} \mathrm{C}$ until required. cDNA was then amplified through real-time PCR by CFX384 Real-Time PCR Detection System (Bio-Rad, CA, USA) using SsoFast EvaGreen Supermix along with forward and reverse primers; the total reaction volume was $5 \mu \mathrm{L}$. Primers for the TSPO [43], $\beta$-actin [43] and Glyceraldehyde 3-phosphate dehydrogenase (GAPDH) [44] genes were used; PCR primer sequences for TSPO forward primer: 5'GGGAGCCTACTTTGTGCGTGG-3'; TSPO reverse primer: 5'CAGGTAAGGATACAGCAAGCGGG-3'; $\beta$-actin forward primer: $5^{\prime}$ ACCAACTGGGACGATATGGAGAAGA- $3^{\prime} ; \beta$-actin reverse primer: 5'-CGCACGATTTCCCTCTCAGC-3'; GAPDH forward primer: 5'CCATGGAGAAGGCTGGGG-3'; and GAPDH reverse primer: 5'CAAAGTTGTCATGGATGACC-3'. PCR amplification run cycle conditions were $98^{\circ} \mathrm{C}$ for 30 seconds and thermo-cycling for 40 cycles 
at $98^{\circ} \mathrm{C}$ for 5 seconds and $63^{\circ} \mathrm{C}$ for 10 seconds, with a final extension at $72^{\circ} \mathrm{C}$ for 10 minutes. To establish a melt curve, the temperature was raised from $75^{\circ} \mathrm{C}$ to $95^{\circ} \mathrm{C}$ at $0.2^{\circ} \mathrm{C}$ increments. Melt curves with multiple peaks which suggested contamination was discarded. The quantitative PCR and relative expression of the TSPO gene was then calculated using the CFX Manager Software, version 2.0 (Bio-rad, CA, USA) using the "Normalized expression $\Delta \Delta C$ " option and both $\beta$ actin and GAPDH as reference genes. All samples were performed in triplicates. Of the 24 samples tested, 2 were excluded due to large gene expression ratios between the GAPDH and $\beta$-actin housekeeping genes.

\section{Autoradiography}

To assess changes in the spatial distribution of TSPO, snap-frozen testicular tissues were sectioned at $20 \mu \mathrm{m}$ in a cryostat, thaw mounted on polylysine-coated slides and stored at $-80^{\circ} \mathrm{C}$ until required. On the day of the experiment, slides were thawed at room temperature and air dried with a cool stream of air. Total binding was determined by incubating slides with $1 \mathrm{nM}$ of ${ }^{3} \mathrm{H}-\mathrm{PK} 11195$ in $130 \mathrm{mM}$ TRIS-HCl buffer for 20 minute at room temperature. Non-specific binding was determined by incubating adjacent sections with $1 \mathrm{nM}$ of ${ }^{3} \mathrm{H}-\mathrm{PK} 11195$ in the presence of $3 \mu \mathrm{M}$ of PK11195. Following incubation, the slides were briefly dipped twice in $130 \mathrm{mM}$ TRIS-HCl buffer, washed twice for 5 minutes in fresh $130 \mathrm{mM}$ TRIS- $\mathrm{HCl}$ at room temperature. The slides were briefly rinsed 3 times in chilled distilled $\mathrm{H} 2 \mathrm{O}$, dried under a cool stream of air and allowed to be air dried overnight. Sections were then exposed to Kodak BioMax MR film along with tritium microscales with known activity concentrations in X-ray film cassettes. Films were developed after 33 days; images were digitized using a GS800 Calibrated Densitometer (Bio-Rad, CA, USA).

\section{Statistical Analysis}

Statistical analyses were performed by GraphPad Prism version 5.04 (La Jolla, CA, USA). Data were analysed with two-way ANOVA (age x treatment) followed by multiple comparisons with Bonferroni correction. Body weight data were analysed with two-way repeated measures ANOVA. Significance was set at $\mathrm{p}<0.05$ and results are presented as mean \pm standard error of the mean.

\section{Results}

\section{HU210 decreased body weight}

Overall, analysis of weight data found significant group $(\mathrm{F}(3,432)=$ $4588, \mathrm{p}<0.0001)$, time $(\mathrm{F}(20,432)=83.15, \mathrm{p}<0.0001)$ and interaction effects between the two variables $(\mathrm{F}(60,432)=12.27, \mathrm{p}<0.0001)$. After arrival from the Animal Resources Centre and prior to HU210 treatment, the body weight of both adult and adolescent rats increased. Multiple comparisons with Bonferonni correction found no significant differences in adult or adolescent groups which were to receive either HU210 or vehicle treatment prior to drug administration ( $p>0.05$ for all time points prior to HU210 or vehicle administration; Figure 1). Following the first injection of HU210 significant differences were found between treatment groups in both adult and adolescent animals in all time points following the first injection $(\mathrm{p}<0.01)$. After 14 days of HU210 treatment both adult and adolescent groups displayed significant reductions in body weight compared to their vehicle controls (adult weight $=361.56 \pm 11.52 \mathrm{~g}$ vs $406.60 \pm 9.10 \mathrm{~g}, \mathrm{p}<0.001$; adolescent weight $=225.42 \pm 5.81 \mathrm{~g}$ vs $276.16 \pm 9.25 \mathrm{~g}, \mathrm{p}<0.001$; Figure
1). However, the dynamics of weight loss in both groups differed; compared to pretreatment after 14 days of HU210 administration adults lost $5.1 \%$ of body weight compared to a gain of $11.6 \%$ in vehicle treated adults, while HU210 treated adolescents gained $38.6 \%$ of body weight compared to gain of $70.0 \%$ in vehicle treated adolescents. Further, adult animals experienced maximum weight loss on the fourth day of HU210 treatment, whereas adolescent animals experienced maximum weight loss on second day of HU210 treatment.

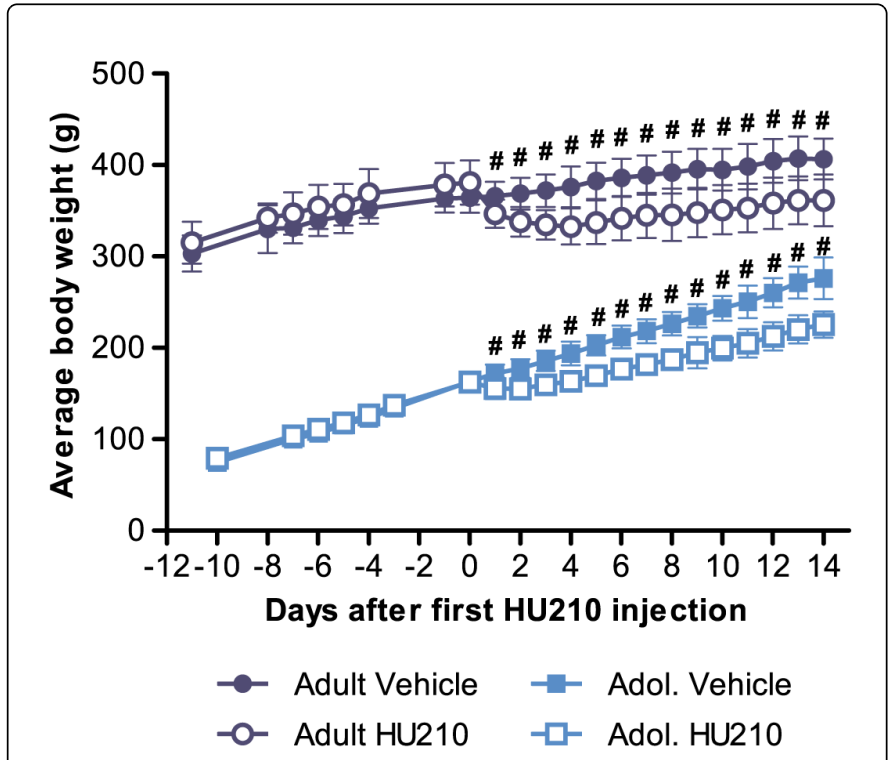

Figure 1: Effect of HU210 on body weight.

Change in the average body weight over time before and after receiving HU210 (100 $\mu \mathrm{g} / \mathrm{kg}$ i.p.) or vehicle over 14 days. HU210 had a strong impact on body weight; differences between HU210 and vehicle treated groups were significant for both adults and adolescent animals for all time points following first injection $(\mathrm{p}<0.01)$.

\section{HU210 decreased ${ }^{3}$ H-PK11195 membrane binding in adult testicular tissues}

Total binding from radioligand membrane binding typically reached a plateau at the 3 highest concentrations of ${ }^{3} \mathrm{H}-\mathrm{PK} 11195$ with lower concentrations forming a rapid sharp curve towards the origin. Non-specific binding displayed a near linear relationship with typical $r^{2}>0.98$. In testicular tissue, two-way ANOVA of Bmax revealed a significant age effect $(\mathrm{F}(1,20)=16.72, \mathrm{p}<0.01)$, a non-significant treatment effect $(F(1,20)=2.71$, NS) and a significant interaction effect between the two variables $(\mathrm{F}(1,20)=91.21, \mathrm{p}<0.001)$. Overall, compared to adults, adolescent testicular Bmax was lower by $54 \%$ $(8015.67 \pm 464.52$ vs $14822.5 \pm 833.54 \mathrm{fmol} / \mathrm{mg}$ protein; Figure $2 \mathrm{~A})$. Analysis of the interaction effect with multiple comparisons revealed that HU210 treated adult animals had a significantly lower TSPO Bmax compared to vehicle control $(12778.33 \pm 857.32$ vs $16866.67 \pm$ $806.61 \mathrm{fmol} / \mathrm{mg}$ protein; $\mathrm{p}<0.001$; Figure $2 \mathrm{~A}$ ), this amounted to an approximately $24 \%$ decrease in TSPO expression following HU210 treatment in adults. However, no significant differences were detected between HU210 treated adolescent animals and their vehicle control $(7145.33 \pm 573.91$ vs $8886 \pm 563.07 \mathrm{fmol} / \mathrm{mg}$ protein $)$. Further, a twoway ANOVA of $\mathrm{Kd}$ revealed a significant age effect $(F(1,20)=27.77$, 
Citation: Chan RHY, Kam WWY, Liu GJ, Zavitsanou K, Banati RB (2014) Testicular Translocator Protein Expression is Differentially Altered by Synthetic Cannabinoid HU210 in Adult and Adolescent Rats. J Addict Res Ther 5: 198. doi:10.4172/2155-6105.1000198

Page 4 of 8

$\mathrm{p}<0.0001)$ with adult animals having a $52 \%$ higher Kd than adolescent animals $(8.09 \pm 0.33$ vs $4.18 \pm 0.37$; Figure $2 \mathrm{~B})$; no significant treatment or interaction effect between the two variables were detected $(F(1,20)=1.17, N S ; F(1,20)=2.48$, NS, respectively). No significant age, treatment or interaction effect in Bmax was seen in the kidney, spleen or liver tissues (Figure 2C,2E,2G). Similarly no significant age, treatment or interaction effect in $\mathrm{Kd}$ was seen in the kidney or spleen tissues (Figure 2D and 2F). In the liver tissues, a significant age effect was observed between adult and adolescent animals in $\mathrm{Kd}$ values $(\mathrm{Kd}=2.15 \pm 0.26$ vs $3.69 \pm 0.4, \mathrm{~F}(1,20)=11.03, \mathrm{p}<0.01$; Figure $2 \mathrm{H})$; no treatment or interaction effect was seen.
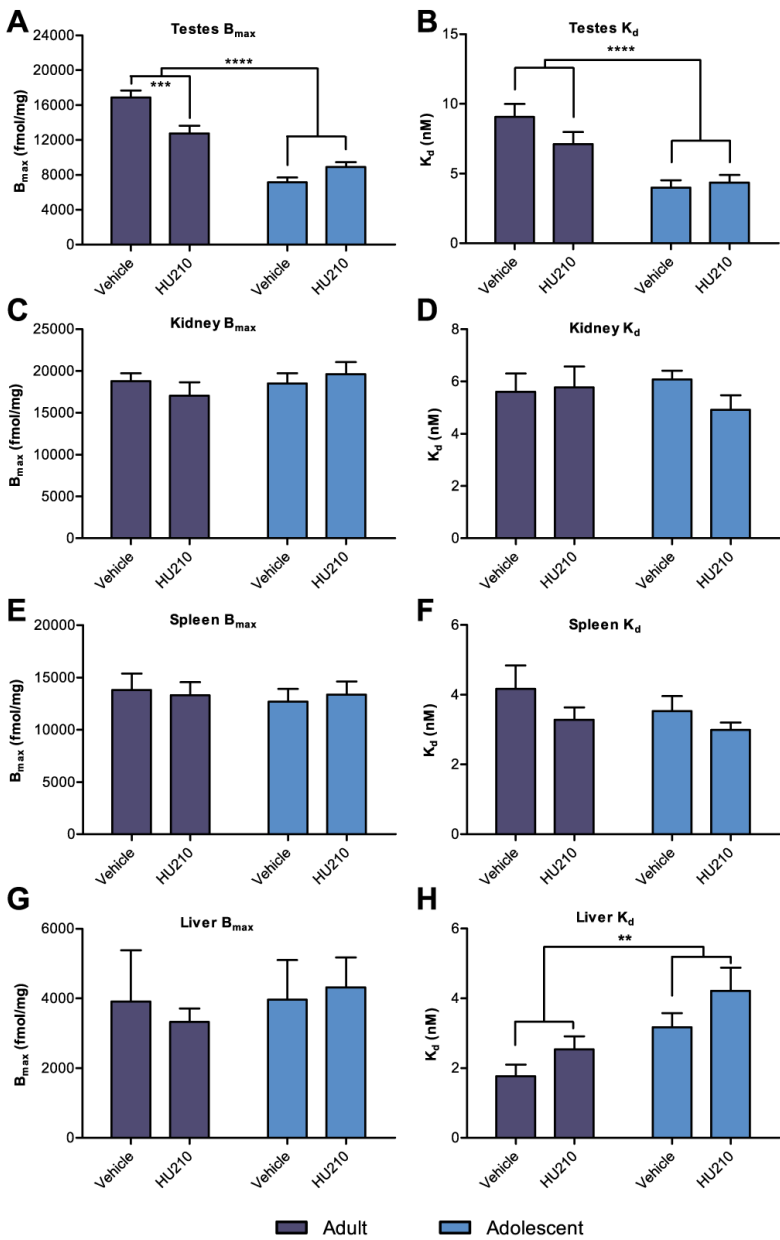

Figure 2: Radio ligand membrane binding results.

${ }^{3} \mathrm{H}-\mathrm{PK} 11195$ membrane binding results from HU210 and vehicle treated adult and adolescent animals. Tissues examined include the $\mathrm{A}$ and $\mathrm{B}$ ) testes, $\mathrm{C}$ and $\mathrm{D}$ ) kidneys, $\mathrm{E}$ and $\mathrm{F}$ ) spleen and $\mathrm{G}$ and $\mathrm{H}$ ) liver. In testes, two-way ANOVA revealed a significant reduction in Bmax in adolescent compared to adult animals ( $p<0.0001)$. Multiple comparisons revealed a significant reduction in Bmax in HU210 treated adults compared to control ( $\mathrm{p}>0.001)$, this was not seen in adolescent animals. In both the testes and liver tissues a significant difference in Kd between adult and adolescent animals was also found ( $\mathrm{p}<0.0001, \mathrm{p}<0.01$ respectively).

\section{HU210 reduced testicular TSPO mRNA in HU210 treated adult rats}

Relative TSPO mRNA expression revealed a significant age $(\mathrm{F}(1,18)=7.24, \quad \mathrm{p}<0.05), \quad$ treatment $\quad(\mathrm{F}(1,18)=6.99, \quad \mathrm{p}<0.05) \quad$ and interaction effect between the two variables $(\mathrm{F}(1,18)=7.01, \mathrm{p}<0.05$; Figure 3). HU210 treated adult animals had a significantly reduced TSPO mRNA expression compared to their vehicle controls $(7.54 \pm$ 2.36 vs $0.58 \pm 0.02 ; \mathrm{p}<0.01)$. This effect was not seen in adolescent animals ( $0.64 \pm 0.05$ vs $0.59 \pm .03$; NS, Figure 3 ).

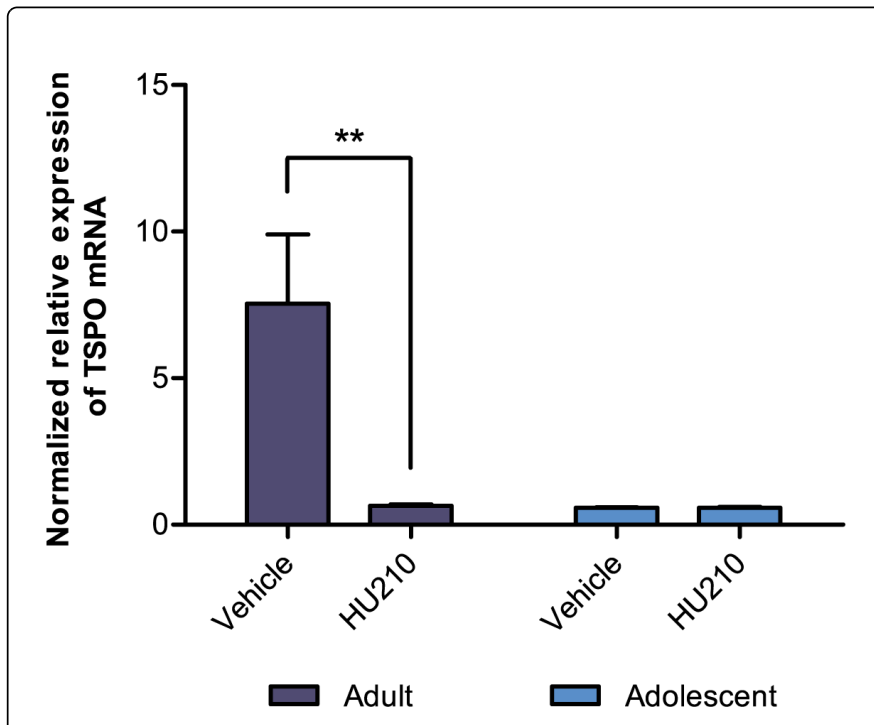

Figure 3: TSPO gene expression.

Normalized relative expression of the testicular TSPO mRNA as determined by $\mathrm{qPCR}$, using GAPDH and $\beta$-actin as housekeeping genes. In adults, compared to vehicle control, HU210 treatment significantly reduced TSPO mRNA expression $(\mathrm{p}<0.01)$. No significant differences were observed between treatments in the adolescent group.

\section{HU210 did not alter interstitial TSPO distribution within testicular tissues}

${ }^{3} \mathrm{H}$-PK11195 autoradiography of testicular tissues showed no alterations in overall TSPO distribution in HU210 treated adults or adolescent animals. TSPO distribution remained the highest in the interstitial space (Figure 4), with distribution being roughly even across the entire section. Non-specific 3H-PK11195 binding was very low and close to unexposed film-autoradiographic background indicating that observed 3H-PK11195 binding is specific and represents TSPO. Since radioligand membrane binding was already used to quantify the level of TSPO protein expression, the intensity of the autoradiographic distribution was not measured as radioligand membrane binding provides a more accurate measure of protein expression. 


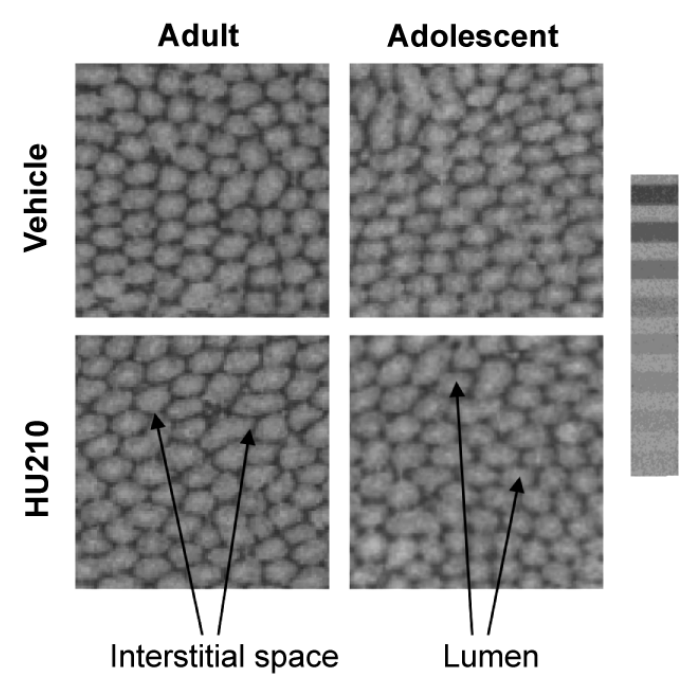

Figure 4: Autoradiographic distribution of TSPO expression.

Representative autoradiographs of testicular TSPO expression from HU210 or vehicle treated adult and adolescent animals. A tritium standard microscale, 4107 to $109 \mathrm{~Bq} / \mathrm{mg}$, is shown next to the images. TSPO expression was determined by autoradiography using $3 \mathrm{H}$ PK11195. Compared to vehicle controls, no alterations to the site of TSPO expression was found in HU210 treated animals; TSPO expression remained high within the interstitial space.

\section{Discussion}

The main findings of this study are that in testicular tissues adolescent animals (PND 48) have an overall lower TSPO protein and gene expression than adult animals (PND 91), and that HU210 appears to cause a decrease in adult testicular TSPO expression while adolescent testicular tissue appears to be unresponsive. TSPO is thought to be involved in the rate limiting step of steroidogenesis $[4,5,19]$. The observed age-related difference in testicular TSPO expression is thus consistent with age-related changes in androgen production associated with development into adulthood. Male rats do not produce mature sperm until PND 53, an indication of sexual maturity, and gradual increases in testosterone are only seen from PND 45-56 [45]. Therefore, when adolescent animals were sacrificed on PND 48, testosterone production and TSPO expression had yet to reach its peak. Separately, results indicated that testicular and liver binding affinity of 3H-PK11195 altered with age, although the significance of this finding is unclear and requires further investigation. Neither the kidney nor spleen tissues demonstrated any age-related changes. These results, with the exception of alterations in affinity, are consistent with previously reported age-related changes in TSPO expression [46,47].

Both, radioligand membrane binding and RT-qPCR, reveal that chronic high-dose administration of synthetic cannabinoid HU210 causes a decrease in testicular TSPO protein and mRNA expression in adult but not adolescent animals. In addition, decreases in TSPO expression appear to occur evenly throughout the testes as indicated by an even autoradiographic spatial distribution pattern. The expression of TSPO as seen in autoradiography is commensurate with the fact that it is primarily expressed in the interstitial space between the seminiferous tubules and is not expressed in the spermatids or sperm [48]. Cannabinoid administration has previously been shown to reduce adult testosterone production and levels [27] possibly through the inhibition of cholesterol esterase and calcium transport through calcium ATPase [31,32]. Given that TSPO is involved in steroidogenesis and hence androgen production, the finding that TSPO expression is decreased in response to HU210 administration indicates that modulation of TSPO may be another possible mechanism by which cannabinoids alter testosterone production. One hypothesis is that testosterone production decreases in response to cannabinoids due to decreases in TSPO facilitated cholesterol transport across the mitochondrial membranes. Although testosterone levels were not directly measured in the present study, previous studies report alterations in testosterone levels and related functions following similar, if not lower, doses of cannabinoids $[30,32,49]$. At present the exact physiological effects of reduced TSPO expression in response to HU210 administration is unknown and warrants further study, particularly in regard to potential alterations to spermatogenesis and sperm health $[50,51]$. A recent study in conditional TSPO knock-out mice casts doubt on the assumption that the TSPO alone is essential for testosterone production in Leydig cells [52]. The regulatory effect of TSPO in testicular tissue may thus be more indirect than currently thought and more closely related to the other roles of the TSPO, such as cell cycle and cell metabolism than steroid biosynthesis per se $[53,54]$.

Unlike adult animals, HU210 did not alter testicular TSPO protein density or distribution, or mRNA levels in adolescent animals. This suggests a decreased vulnerability to cannabinoids or the presence of other adaptive mechanisms. Previous studies using similar doses and treatment regimens of HU210 as the present study have reported alterations in various brain neurotransmitter systems in adult but not adolescent animals [39-42]. The reasons why adolescent animals appear to be less sensitive to cannabinoids, as observed in this study and previous studies, remains unclear. Adolescent animals find cannabinoids less aversive than adults in place and taste aversion tests and emit less vocalisations in response to cannabinoid administration [38] but cannabinoids have greater long-term behavioural detrimental effects to adolescent animals [36-38]. It is possible that the reduced aversion and sensitivity to cannabinoids results in a greater rate of long-term effects. Similar observations have been reported with alcohol, which have found that during adolescence alcohol may interact with reward neurocircuitry and corticolimbic structure and functions to promote maladaptive behaviours leading to addiction [55]. Physiologically, a failure to regulate biochemical receptor systems, including TSPO expression, could potentially increase the susceptibility of adolescent animals to the long-term detrimental effects of cannabinoids.

HU210 at doses similar to the ones used in the present study, have previously been reported to produce anxiogenic responses in a variety of tests, including the defensive withdrawal test [56] and the X-maze [57]. Further, HU210 produces a persistent enhancement of emotional responses to novel environments following withdrawal [57]. In animal models, chronic stress such as inescapable shock and swim stress alters TSPO expression in a variety of organs, in particular the kidney [58-60], while in humans, anxiety disorders including generalized anxiety disorder, panic disorder and post-traumatic stress disorder alters TSPO expression in various blood cells including platelets and monocytes [61-63]. To assess whether the anxiogenic properties of 
HU210 produced changes in TSPO expression similar to that of chronic stress or anxiety disorders, we examined the spleen as it is known to contain a large reservoir of platelets and monocytes [64,65], the kidney and liver tissues. The results reveal no significant changes in TSPO expression following HU210 administration in either adult or adolescent animals in the kidney, spleen or liver. This was particular surprising given the significant decreases in body weight gain, a response normally associated with stress, in HU210 treated adult and adolescent animals [66]. However, HU210 induced weight loss may be accounted for by the activation of the CB1 receptor system which is linked with the regulation of appetite, energy balance and metabolism $[67,68]$. The published literature and our own data suggest that the tissue-specific transcriptional regulation of TSPO is dependent on the stressor used. Therefore, additional studies are required to clarify the relationship between cannabinoids, anxiety and TSPO expression. In summary, this study demonstrates that chronic administration of HU210 alters TSPO expression in an age-specific manner by reducing adult but not adolescent testicular TSPO expression.

\section{Acknowledgements}

We would like to thank Mathieu Verdurand and Victoria Dalton for their assistance with training and injection of HU210, Emma Millard for her technical assistance with animal dissection and organ collection.

\section{Conflicts of interest}

The authors have no conflicts of interest to declare. This research received no specific grant from any funding agency in the public, commercial, or not-for-profit sectors.

\section{References}

1. Anholt RR, Pedersen PL, De Souza EB, Snyder SH (1986) The peripheraltype benzodiazepine receptor. Localization to the mitochondrial outer membrane. J Biol Chem 261: 576-583.

2. De Souza EB, Anholt RR, Murphy KM, Snyder SH, Kuhar MJ (1985) Peripheral-type benzodiazepine receptors in endocrine organs: autoradiographic localization in rat pituitary, adrenal, and testis Endocrinology 116: 567-573.

3. Krueger KE, Papadopoulos V (1990) Peripheral-type benzodiazepine receptors mediate translocation of cholesterol from outer to inner mitochondrial membranes in adrenocortical cells. J Biol Chem 265: 15015-15022.

4. Papadopoulos V, Amri H, Boujrad N, Cascio C, Culty M, et al. (1997) Peripheral benzodiazepine receptor in cholesterol transport and steroidogenesis. Steroids 62: 21-28.

5. Mukhin AG, Papadopoulos V, Costa E, Krueger KE (1989) Mitochondrial benzodiazepine receptors regulate steroid biosynthesis. Proc Natl Acad Sci U S A 86: 9813-9816.

6. Gavish M, Bachman I, Shoukrun R, Katz Y, Veenman L, et al. (1999) Enigma of the peripheral benzodiazepine receptor. Pharmacol Rev 51: 629-650.

7. Taketani S, Kohno H, Furukawa T, Tokunaga R (1995) Involvement of peripheral-type benzodiazepine receptors in the intracellular transport of heme and porphyrins. J Biochem 117: 875-880.

8. Verma A, Nye JS, Snyder SH (1987) Porphyrins are endogenous ligands for the mitochondrial (peripheral-type) benzodiazepine receptor. Proc Natl Acad Sci U S A 84: 2256-2260.

9. Alho H, Varga V, Krueger KE (1994) Expression of mitochondrial benzodiazepine receptor and its putative endogenous ligand diazepam binding inhibitor in cultured primary astrocytes and C-6 cells: relation to cell growth. Cell Growth Differ 5: 1005-1014.
10. Corsi L, Geminiani E, Baraldi M (2008) Peripheral benzodiazepine receptor (PBR) new insight in cell proliferation and cell differentiation review. Curr Clin Pharmacol 3: 38-45.

11. Hirsch T, Decaudin D, Susin SA, Marchetti P, Larochette N, et al. (1998) PK11195, a ligand of the mitochondrial benzodiazepine receptor, facilitates the induction of apoptosis and reverses Bcl-2-mediated cytoprotection. Exp Cell Res 241: 426-434.

12. Sutter AP, Maaser K, Grabowski P, Bradacs G, Vormbrock K, et al (2004) Peripheral benzodiazepine receptor ligands induce apoptosis and cell cycle arrest in human hepatocellular carcinoma cells and enhance chemosensitivity to paclitaxel, docetaxel, doxorubicin and the Bcl-2 inhibitor HA14-1. J Hepatol 41: 799-807.

13. Bessler H, Weizman R, Gavish M, Notti I, Djaldetti M (1992) Immunomodulatory effect of peripheral benzodiazepine receptor ligands on human mononuclear cells. J Neuroimmunol 38: 19-25.

14. Waterfield JD, McGeer EG, McGeer PL (1999) The peripheral benzodiazepine receptor ligand PK 11195 inhibits arthritis in the MRLlpr mouse model. Rheumatology (Oxford) 38: 1068-1073.

15. Li H, Papadopoulos V (1998) Peripheral-type benzodiazepine receptor function in cholesterol transport. Identification of a putative cholesterol recognition/interaction amino acid sequence and consensus pattern. Endocrinology 139: 4991-4997.

16. Jamin N, Neumann JM, Ostuni MA, Vu TK, Yao ZX, et al. (2005) Characterization of the cholesterol recognition amino acid consensus sequence of the peripheral-type benzodiazepine receptor. Mol Endocrinol 19: 588-594.

17. Jefcoate CR, McNamara BC, Artemenko I, Yamazaki T (1992) Regulation of cholesterol movement to mitochondrial cytochrome P450scc in steroid hormone synthesis. J Steroid Biochem Mol Biol 43: 751-767.

18. Privalle CT, Crivello JF, Jefcoate CR (1983) Regulation of intramitochondrial cholesterol transfer to side-chain cleavage cytochrome P-450 in rat adrenal gland. Proc Natl Acad Sci U S A 80: 702-706.

19. Pandak WM, Ren S, Marques D, Hall E, Redford K, et al. (2002) Transport of cholesterol into mitochondria is rate-limiting for bile acid synthesis via the alternative pathway in primary rat hepatocytes. J Biol Chem 277: 48158-48164.

20. Costa B, Da Pozzo E, Martini C (2012) Translocator protein as a promising target for novel anxiolytics. Curr Top Med Chem 12: 270-285.

21. Rone MB, Fan J, Papadopoulos V (2009) Cholesterol transport in steroid biosynthesis: role of protein-protein interactions and implications in disease states. Biochim Biophys Acta 1791: 646-658.

22. Rupprecht R, Papadopoulos V, Rammes G, Baghai TC, Fan J, et al. (2010) Translocator protein $(18 \mathrm{kDa})$ (TSPO) as a therapeutic target for neurological and psychiatric disorders. Nat Rev Drug Discov 9: 971-988.

23. Bitran D, Foley M, Audette D, Leslie N, Frye CA (2000) Activation of peripheral mitochondrial benzodiazepine receptors in the hippocampus stimulates allopregnanolone synthesis and produces anxiolytic-like effects in the rat. Psychopharmacology (Berl) 151: 64-71.

24. Kita A, Furukawa K (2008) Involvement of neurosteroids in the anxiolytic-like effects of AC-5216 in mice. Pharmacol Biochem Behav 89: 171-178.

25. Serra M, Madau P, Chessa MF, Caddeo M, Sanna E, et al. (1999) 2Phenyl-imidazo[1,2-a]pyridine derivatives as ligands for peripheral benzodiazepine receptors: stimulation of neurosteroid synthesis and anticonflict action in rats. Br J Pharmacol 127: 177-187.

26. Verleye M, Akwa Y, Liere P, Ladurelle N, Pianos A, et al. (2005) The anxiolytic etifoxine activates the peripheral benzodiazepine receptor and increases the neurosteroid levels in rat brain. Pharmacol Biochem Behav 82: $712-720$.

27. Gorzalka BB, Hill MN, Chang SC (2010) Male-female differences in the effects of cannabinoids on sexual behavior and gonadal hormone function. Horm Behav 58: 91-99.

28. Dalterio S, Bartke A, Burstein S (1977) Cannabinoids inhibit testosterone secretion by mouse testes in vitro. Science 196: 1472-1473. 
29. Kolodny RC, Masters WH, Kolodner RM, Toro G (1974) Depression of plasma testosterone levels after chronic intensive marihuana use. N Engl J Med 290: 872-874

30. Rosenkrantz H, Esber HJ (1980) Cannabinoid-induced hormone changes in monkeys and rats. J Toxicol Environ Health 6: 297-313.

31. Burstein S, Hunter SA, Shoupe TS (1979) Site of inhibition of leydig cell testosterone synthesis by delta 1-tetrahydrocannabinol. Mol Pharmacol 15: 633-640.

32. Dalterio SL, Bernard SA, Esquivel CR (1987) Acute delta 9tetrahydrocannabinol exposure alters $\mathrm{Ca} 2+$ ATPase activity in neuroendocrine and gonadal tissues in mice. Eur J Pharmacol 137: 91-100.

33. Wenger T, Ledent C, Csernus V, Gerendai I (2001) The central cannabinoid receptor inactivation suppresses endocrine reproductive functions. Biochem Biophys Res Commun 284: 363-368.

34. Hall W, Solowij N, Lemon J (2001) The Health and Psychological Consequences of Cannabis Use. Australian Government Publishing Services: Canberra,

35. Viveros MP, Llorente R, Moreno E, Marco EM (2005) Behavioural and neuroendocrine effects of cannabinoids in critical developmental periods. Behav Pharmacol 16: 353-362.

36. Bambico FR, Nguyen NT, Katz N, Gobbi G (2010) Chronic exposure to cannabinoids during adolescence but not during adulthood impairs emotional behaviour and monoaminergic neurotransmission. Neurobiol Dis 37: 641-655.

37. O'Shea M, Singh ME, McGregor IS, Mallet PE (2004) Chronic cannabinoid exposure produces lasting memory impairment and increased anxiety in adolescent but not adult rats. J Psychopharmacol 18: 502-508.

38. Quinn HR, Matsumoto I, Callaghan PD, Long LE, Arnold JC, et al. (2008) Adolescent rats find repeated Delta(9)-THC less aversive than adult rats but display greater residual cognitive deficits and changes in hippocampal protein expression following exposure. Neuropsychopharmacology 33: 1113-1126.

39. Dalton VS, Wang H, Zavitsanou K (2009) HU210-induced downregulation in cannabinoid CB1 receptor binding strongly correlates with body weight loss in the adult rat. Neurochem Res 34: 1343-1353.

40. Dalton VS, Zavitsanou K (2010) Differential treatment regimen-related effects of cannabinoids on D1 and D2 receptors in adolescent and adult rat brain. J Chem Neuroanat 40: 272-280.

41. Verdurand M, Dalton VS, Zavitsanou K (2010) GABA(A) receptor density is altered by cannabinoid treatment in the hippocampus of adult but not adolescent rats. Brain Res 1351: 238-245.

42. Zavitsanou K, Wang H, Dalton VS, Nguyen V (2010) Cannabinoid administration increases 5HT1A receptor binding and mRNA expression in the hippocampus of adult but not adolescent rats. Neuroscience 169: 315-324.

43. Moran LB, Duke DC, Turkheimer FE, Banati RB, Graeber MB (2004) Towards a transcriptome definition of microglial cells. Neurogenetics 5: 95-108.

44. Dveksler GS, Basile AA, Dieffenbach CW (1992) Analysis of gene expression: use of oligonucleotide primers for glyceraldehyde-3phosphate dehydrogenase. PCR Methods Appl 1: 283-285.

45. Harris GC, Levine JE (2003) Pubertal acceleration of pulsatile gonadotropin-releasing hormone release in male rats as revealed by microdialysis. Endocrinology 144: 163-171.

46. Kurumaji A, Toru M (1996) Postnatal development of peripheral-type benzodiazepine receptors in rat brain and peripheral tissues. Brain Res Dev Brain Res 97: 148-151.

47. Mercer KA, Weizman R, Gavish M (1992) Ontogenesis of peripheral benzodiazepine receptors: demonstration of selective up-regulation in rat testis as a function of maturation. J Recept Res 12: 413-425.

48. Morohaku K, Phuong NS, Selvaraj V (2013) Developmental expression of translocator protein/peripheral benzodiazepine receptor in reproductive tissues. PLoS One 8: e74509.
49. Dalterio S, Mayfield D, Bartke A, Morgan W (1985) Effects of psychoactive and non-psychoactive cannabinoids on neuroendocrine and testicular responsiveness in mice. Life Sci 36: 1299-1306.

50. Walker WH (2011) Testosterone signaling and the regulation of spermatogenesis. Spermatogenesis 1: 116-120.

51. Lewis SE, Paro R, Borriello L, Simon L, Robinson L, et al. (2012) Longterm use of HU210 adversely affects spermatogenesis in rats by modulating the endocannabinoid system. Int J Androl 35: 731-740.

52. Morohaku K, Pelton SH, Daugherty DJ, Ronald Butler W, Deng W, et al. (2013) Translocator Protein/Peripheral Benzodiazepine Receptor Is Not Required for Steroid Hormone Biosynthesis. Endocrinology

53. Caballero B, Veenman L, Gavish M (2013) Role of mitochondrial translocator protein $(18 \mathrm{kDa})$ on mitochondrial- related cell death processes. Recent Pat Endocr Metab Immune Drug Discov 7: 86-101.

54. Fan J, Lindemann P, Feuilloley MG, Papadopoulos V (2012) Structural and functional evolution of the translocator protein $(18 \mathrm{kDa})$. Curr Mol Med 12: 369-386.

55. Izenwasser S (2005) Differential effects of psychoactive drugs in adolescents and adults. Crit Rev Neurobiol 17: 51-67.

56. Rodríguez de Fonseca F, Rubio P, Menzaghi F, Merlo-Pich E, Rivier J, et al. (1996) Corticotropin-releasing factor (CRF) antagonist [DPhe12,Nle21,38,C alpha MeLeu37]CRF attenuates the acute actions of the highly potent cannabinoid receptor agonist HU-210 on defensivewithdrawal behavior in rats. J Pharmacol Exp Ther 276: 56-64.

57. Giuliani D, Ferrari F, Ottani A (2000) The cannabinoid agonist HU 210 modifies rat behavioural responses to novelty and stress. Pharmacol Res 41: 47-53.

58. Avital A, Richter-Levin G, Leschiner S, Spanier I, Veenman L, et al. (2001) Acute and repeated swim stress effects on peripheral benzodiazepine receptors in the rat hippocampus, adrenal, and kidney. Neuropsychopharmacology 25: 669-678.

59. Drugan RC, Basile AS, Crawley JN, Paul SM, Skolnick P (1986) Inescapable shock reduces [3H]Ro 5-4864 binding to "peripheral-type" benzodiazepine receptors in the rat. Pharmacol Biochem Behav 24: 1673-1677.

60. Holmes PV, Stringer AP, Drugan RC (1992) Impact of psychological dynamics of stress on the peripheral benzodiazepine receptor. Pharmacol Biochem Behav 42: 437-444.

61. Gavish M, Laor N, Bidder M, Fisher D, Fonia O, et al. (1996) Altered platelet peripheral-type benzodiazepine receptor in posttraumatic stress disorder. Neuropsychopharmacology 14: 181-186.

62. Pini S, Martini C, Abelli M, Muti M, Gesi C, et al. (2005) Peripheral-type benzodiazepine receptor binding sites in platelets of patients with panic disorder associated to separation anxiety symptoms.Psychopharmacology (Berl) 181: 407-411.

63. Rocca P, Beoni AM, Eva C, Ferrero P, Zanalda E, et al. (1998) Peripheral benzodiazepine receptor messenger RNA is decreased in lymphocytes of generalized anxiety disorder patients. Biol Psychiatry 43: 767-773.

64. Penny R, Rozenberg MC, Firkin BG (1966) The splenic platelet pool. Blood 27: 1-16.

65. Swirski FK, Nahrendorf M, Etzrodt M, Wildgruber M, Cortez-Retamozo $\mathrm{V}$, et al. (2009) Identification of splenic reservoir monocytes and their deployment to inflammatory sites. Science 325: 612-616.

66. Giuliani D, Ottani A, Ferrari F (2000) Effects of the cannabinoid receptor agonist, HU 210, on ingestive behaviour and body weight of rats. Eur J Pharmacol 391: 275-279.

67. Bellocchio L, Cervino C, Pasquali R, Pagotto U (2008) The endocannabinoid system and energy metabolism. J Neuroendocrinol 20: 850-857.

68. Bermudez-Silva FJ, Viveros MP, McPartland JM, Rodriguez de Fonseca F (2010) The endocannabinoid system, eating behavior and energy homeostasis: the end or a new beginning?Pharmacol Biochem Behav 95: 375-382. 